\title{
Condições e Obstáculos ao Empreendedorismo no Brasil
}

\author{
Conditions and Barriers to Entrepreneurship in Brazil
}

\section{Daniel da Rosa Eslabãoํㅜ Fabrizio Bon Vecchio ${ }^{2}$}

1 E-mail:

daniel filosofo@hotmail.com

Universidade do Porto

2 E-mail:

fabrizio@vecchioassociados.com.br Universidade de Trás os Montes e alto Douro
Resumo: O presente artigo versa sobre os fatores estruturais, sóciopolíticos, culturais, organizacionais e institucionais que suportam as atividades empreendedoras no campo empresarial. Em nosso estudo apresentamos de forma resumida os resultados do estudo Global Entrepreneurship Monitor (GEM), no qual focaremos os resultados obtidos em relação ao Brasil. Deste modo, visamos verificar as condições que afetam o empreendedorismo nacional deste país. Iniciamos nossa reflexão pela apresentação da origem e do significado do ato de empreender, tal qual concebido originalmente pela ciência econômica. Em um segundo momento, expomos alguns dados atuais acerca das características do empreendedorismo brasileiro, para finalmente apresentar o resultado comentado do estudo do GEM-Brasil. Concluímos que embora o Brasil seja um país que tem evoluído em termos de um maior empreendedorismo de oportunidade, como uma conseqüência da expansão econômica que viveu o país nos anos recentes, onde o empreendedorismo de necessidade começa a dar lugar a uma classe empresarial mais bem preparada e escolarizada; este setor ainda carece de maiores aportes em termos de educação e capacitação, bem como maiores investimentos em $\mathrm{P} \& \mathrm{D}$, o que significaria a alavancagem necessária a empreendimentos inovadores com grande potencial de internacionalização, haja vista as novas redes de relações internacionais estabelecidas nas últimas décadas, na qual se inclui a CPLP.

Palavras-chave: Desenvolvimento Econômico; Empreendedorismo; Inovação; Organização.

\begin{abstract}
This article deals with the structural, socio-political, culturaland institutional factors that support entrepreneurial activities in the business area. This study presents briefly the results of the Global Entrepreneurship Monitor study (GEM), which will focus on the results obtained in relation to Brazil. Thus, we aim to verify the conditions thataffect the national entrepreneurship of this country. We begin our analysis by presenting the origin and meaning of the act of undertaking, as originally conceived by economics. In a second moment, we expose some current data about the characteristics of the Brazilian entrepreneurship to finally present the results of the study commented GEM-Brazil. We conclude that although Brazil is a country that has evolved in terms of a greater entrepreneurial opportunity as a result of the economic expansion that lived the country in recent years, where entrepreneurship need begins to give way to a business class better prepared and educated; this sector still requires higher investments in education and training, and greater investment to $R \& D$, which would mean the necessary leverage to innovative projects with great potentialfor internationalization, given the new international relations networksestablished in recent decades, in which includes the CPLP.
\end{abstract}

Keywords: Economic Development; Entrepreneurship; Innovation; Organization. 


\section{Introdução}

Os empreendimentos privados constituem a base do sistema capitalista e da prosperidade das nações, especialmente pela sua capacidade direta de geração de empregos e renda e subsidiariamente na geração de tributos, que permitem ao Estado auferir recursos para a prestação dos seus serviços e a promoção do bem estar social. Ao longo das duas últimas décadas do século passado foi observado um grande interesse pelo estudo das atividades empreendedoras. Louis Jacques Filon, um dos mais renomados especialistas sobre o assunto, afirma que naquele período o número de publicações anuais pertinentes a este tópico excedia a mil títulos (FILON, 1999). O termo empreendedorismo começou a ser empregado pelos economistas franceses entre os séculos XVIII e XIX. Dentre os autores que se dedicaram ao tema devemos destacar o pensador franco-irlandês Richard Cantillon (1680-1734), que em uma obra póstuma intitulada Ensaio Sobre a Natureza do Comércio em Geral (1755), publicada originalmente em francês, utiliza por vez primeira o termo entrepreneur, para se referir ao empreendedor de risco. Mais tarde Jean-Batiste Say irá distinguir entre a atividade capitalista em geral e a atividade empreendedora, que para ele deveria ser portadora de inovação (FILON, 1999). Na obra de Karl Marx (1818-1883), podemos encontrar a atividade empreendedora associada aos processos de acumulação de capital (Marx, 2014). Josef Schumpeter (2010) foi um dos teóricos que nos tempos modernos estudou o empreendedorismo (entrepeneurship). Para ele a atividade empreendedora está associada às estruturas sócio-políticas e institucionais relativas às suas capacidades de proteção as atividades empreendedoras, como é o caso das leis de registros e patentes. Além disso, Schumpeter também destaca o papel do empreendedorismo na transição entre o capitalismo competitivo e o capitalismo dos grandes negócios (Big-business). Estudos recentes associam a capacidade de empreender com o desenvolvimento econômico das sociedades (Ahmed; Seymours, 2008). Ao longo do século XX e neste início de século XXI, o tópico em questão tem atraído interesse de diferentes campos científicos, desde a Sociologia e a Antropologia até as Ciências Econômicas e as Ciências Gerenciais. Perfazendo um amplo espectro de interesse é natural que este tema tenha originado um grande número de perspectivas de estudo. No Brasil, os estudos pertinentes ao empreendedorismo se tornaram expressivos a partir dos anos 1990s e nos últimos anos tem chamado a atenção devido à crescente participação do país no cenário internacional. Uma vez que, para além da expressão econômica brasileira, tomada isoladamente, que o alçou a posição de uma das maiores economias mundiais, a 
diplomacia brasileira também tem se articulado com outras nações em diferentes blocos estratégicos, tais como o grupo dos BRIC (Brasil, Rússia, Índia, China), MERCOSUL, UNASUL e mesmo que forma ainda tímida junto aos países da CPLP. Deste modo, a relevância política brasileira no cenário internacional, toma expressão cada vez mais significativa não apenas em termos regionais, na América do Sul, como também nas relações multilaterais de diferentes grupos de países. Nosso artigo visa realizar uma breve revisão bibliográfica pertinente aos obstáculos enfrentados pela atividade empreendedora no Brasil. Tomaremos como parâmetro três dimensões: (1) os processos de abertura de empresa, (2) a burocracia tributária e (3) a preparação individual do empreendedor para o exercício da atividade empresarial. Antes de adentrarmos nestes aspectos iremos apresentar a caracterização geral do empreendedorismo no Brasil, com o intuito de melhor situar o leitor ante a realidade do setor.

\section{Brasil: uma nação empreendedora}

O relatório: Estatísticas de empreendedorismo de 2012 (IBGE, 2014); enfatiza os seguintes aspectos relativos ao empreendedorismo empresarial no Brasil: em primeiro lugar a capacidade de geração de empregos proporcionada pelas empresas e em segundo lugar as empresas de alto crescimento, superior a vinte por cento ao ano e seu impacto econômico. Nas palavras de Luiz Eduardo Pereira Barreto filho, então presidente do SEBRAE:

No grupo dos Empreendedores Iniciais, os que têm até 3,5 anos de atividade, também considerado o grupo de entrada no empreendedorismo $51 \%$ são mulheres e $53 \%$ têm até 34 anos. Isso mostra que a opção de empreender é uma forte alternativa de ocupação, principalmente, para as mulheres e os mais jovens. A escolaridade também vem aumentando a cada ano, acompanhando uma tendência mais ampla da economia brasileira. No grupo dos Empreendedores Iniciais, quase $50 \%$ tem segundo grau completo ou mais, o maior patamar da série histórica. Com base nisso, é possível reforçar a máxima de que o empreendedorismo é um dos fenômenos mais importantes para o desenvolvimento de um país, devendo ainda, por muitas décadas desempenhar relevante papel no desenvolvimento de nossa sociedade (Luiz E. P. Barreto Filho, in: Greco, 2014, p. 09).

No perfil empresarial acima descrito observamos que nunca foi tão elevada a participação do gênero feminino entre os empreendedores nacionais, superando pela primeira vez o gênero masculino em termos de empreendedores. O que demonstra o potencial dos 
empreendimentos privados como um fator de emancipação social para a mulher brasileira, permitindo seu empoderamento (Empowerment) e a conquista de um status social mais elevado. Além disso, o fato de grande número destes empreendedores possuírem até 34 anos de idade revela o quanto este outro segmento, que é o da população jovem, é representado por mais da metade dos empresários iniciantes no país. Dotados estes de uma maior qualificação em relação às gerações anteriores. Podemos então afirmar que a atividade empresarial está a contribuir para uma maior integração social destes segmentos.

Um aspecto que podemos levar em conta para tentar entender o a participação de pessoas com menos de 35 anos nesse estudo, e a própria dificuldade que cada vez mais se observa de ingresso ou manutenção no mercado formal de trabalho com o esfriamento da Economia brasileira já a partir de 2011.

No que diz respeito às motivações pessoais relativas ao empreendimento de negócios, podemos dividi-las em duas grandes categorias: em primeiro lugar aquela motivada pela percepção de oportunidade de negócios e em segundo lugar aquela motivada pela condição pessoal de necessidade. Enquanto o empreendedorismo de oportunidade possui uma perspectiva de médio e longo prazo em relação ao ramo escolhido, visando a possibilidade de lucros expressivos (motivação capitalista) o empreendedorismo por necessidade se caracteriza por aqueles que: "Decidem empreender por não possuírem melhores opções de emprego (...)" (Greco, 2014, p. 36). Muitas vezes o empreendedor por necessidade se vê obrigado a iniciar um trabalho por conta própria como uma alternativa ao desemprego. Podemos dizer que aquele que empreende tendo como sua motivação principal a percepção de nichos de mercado a serem explorados (oportunidades), possui maior vocação em relação ao mundo dos negócios do que os movidos por necessidade. Estudos têm apontado correlações entre as motivações ao empreendedorismo e o estágio de desenvolvimento econômico das sociedades e a tipologia das motivações. Deste modo, podemos observar que o elevado grau de crescimento econômico observado no Brasil nos primeiros anos do século XXI proporcionou uma mudança no perfil do empreendedorismo nacional, uma vez que entre os anos de 2002 e 2013-14, a taxa de empreendedorismo motivada pela percepção de oportunidade cresceu de 42,4\% para 71\% (Greco, 2014). O que pode ser associado diretamente ao maior grau de desenvolvimento econômico verificado naquele período. Além dos aspectos acima mencionados é importante salientar que o Brasil é um país 
continental, com mais de duzentos milhões de habitantes, que alem de sua diversidade cultural também possui diferenças econômicas relevantes no desenvolvimento econômico de cada uma das suas cinco grandes regiões. Portanto, o grau de iniciativa empresarial e o perfil dos investidores estarão sujeitas as realidades locais.

Quando tomamos como parâmetro de análise do empreendedorismo o TEA, que é a taxa específica de empreendedores iniciais, que é o indicador do percentual da população economicamente ativa que em um determinado período inicia uma atividade empresarial, observamos que no caso brasileiro este índice chega a 17, 2\%. Sendo ligeiramente maior entre as mulheres $(17,5)$ e um pouco menor no gênero masculino $(17 \%)$. Este índice de envolvimento da população em atividades empresariais no Brasil é superior ao de alguns países desenvolvidos, como a Alemanha (5,3\%) e os Estados Unidos (13,8\%), mas ficando atrás do México, que possui um TEA de 19\% (Greco, 2014).

De um modo geral, podemos caracterizar a atividade empreendedora brasileira como extremamente relevante e expressiva sob o ponto de vista do percentual da população que se envolve diretamente nesta atividade. Além dos benefícios econômicos, verifica-se o caráter inclusivo na expansão dos negócios por conta própria crescentes na última década. Pois, envolve um expressivo contingente de jovens e de mulheres, que através do trabalho empreendedor vencem as barreiras da exclusão que nas sociedades modernas costumam atingir estes segmentos sociais. No que diz respeito aos fatores que impulsionam a atividade empreendedora no Brasil, o país de encontra mais motivado pela capacidade de eficiência, ao lado de países como China, México e Rússia, do que pela inovação, como o que verificamos em países de alto desenvolvimento tais como Alemanha e EUA. Embora tenha ultrapassado o nível das sociedades cujo desenvolvimento empresarial se deve a fatores excepcionais, como ocorre na Índia ou Bolívia.

\section{Fatores e obstáculos ao empreendedorismo no Brasil}

A pesquisa internacional General Entrepreneurship Monitor (GEM) de 2014, identificou no Brasil uma série de fatores que favorecem e outros que ainda carecem de maior aprimoramento para alavancar o desenvolvimento das atividades empresariais no país. A pesquisa daquele ano verificou uma lista de nove condições que tendem a favorecer o empreendedorismo. Estes itens fazem parte de um levantamento global e são aplicados 
em cerca de setenta países que participam deste levantamento, estes fatores são: (1) Apoio Financeiro, (2) Políticas governamentais, (3) Programas públicos e privados de apoio a atividade empresarial, (4) Educação e capacitação, (5) Pesquisa e Desenvolvimento, (6) Infraestrutura Comercial e Profissional, (7) Acesso ao Mercado e Barreiras à entrada, (8) Acesso à infraestrutura física, (9) Normas culturais e sociais. Estes itens acima relacionados perfazem o que traduzimos livremente como Quadro de Condições para o empreendedorismo (Entrepreuneurial Framework Conditions), cuja sigla em língua inglesa é EFC. Este quadro foi elaborado com base em entrevistas a empreendedores iniciantes e também através de entrevistas junto a pesquisadores especialistas no assunto. Os resultados obtidos seguem abaixo, conforme relatado por Greco (2014).

Neste quesito, apenas o acesso ao mercado (item sete) e o acesso à infraestrutura física (item oito), foram considerados altamente favoráveis. Outras três condições foram consideradas favoráveis, mas em situação precária, pois os resultados apresentaram baixa pontuação: estes foram: as Normas Culturais e Sociais (item nove); a Infraestrutura Comercial e Profissional (item seis) e o Apoio Financeiro (item um). Nestes três quesitos, percebemos que embora existam condições ofertadas estas ainda podem ser melhoradas ou foram consideradas insuficientes.

Entre as condições negativas encontramos as Políticas governamentais (item dois) e os Programas Governamentais e Privados de apoio a atividade empresarial (item três), seja nos níveis dos municípios, dos estados ou nacional. Estes dados vão ao encontro de uma vasta bibliografia que aponta na burocracia estatal um forte obstáculo ao empreendedorismo.

No entanto os piores indicadores ficaram segundo este levantamento com as condições de educação e capacitação (item quatro) e aqueles relativos à Pesquisa e Desenvolvimento (P\&D, item cinco). Este é um dado revelador, pois reflete diretamente no fato da sociedade brasileira se encontrar entre aquelas que empreendem por oportunidade, mas se apresentam com uma baixa capacidade de gerar inovação, uma vez que a qualificação dos quadros empreendedores, sua maior capacitação e educação, tanto quanto as possibilidades de investimento em P\&D afetam diretamente a possibilidade de gerar negócios inovadores. Em uma relação direta do investimento e da capacitação, embora este não seja o único fator relevante (Bessant; Tidd, 2009). 


\section{Recursos para o desenvolvimento empresarial brasileiro}

$\mathrm{Na}$ atualidade o Brasil possui uma vasta rede de universidades públicas e privadas e Institutos Tecnológicos. Muitas destas Instituições possuem cursos na área de Gestão, o que constitui um sistema de formação para futuros empresários e gestores. Além disso, existe no país o SEBRAE, ou Serviço Brasileiro de Apoio às Micro e Pequenas Empresas. Atuante desde o início da década de 1970s (1972), como entidade privada sem finalidade de lucro dedicada não apenas ao apoio aos empresários estabelecidos, como também como um órgão fomentador do empreendedorismo. Além do SEBRAE existem outras entidades setoriais, que visam contribuir para o que perfaz os serviços nacionais de aprendizagem e que abrangem as seguintes instituições e segmentos econômicos: SENAR (Rural), SENAC (Comercial), SESCOOP (Cooperativismo), SENAI (Industrial) e SENAT (Transporte). Da letra inicial de cada uma das entidades deriva o termo Sistema "S". As origens deste Sistema remontam aos anos de 1940s e se encontram atualmente distribuídos por todo território nacional.

Podemos então afirmar, que existe o suporte de apoio educacional aos trabalhadores, gestores e empreendedores em diversos campos das atividades econômicas. Embora os investimentos em tecnologias, pesquisa e desenvolvimento ainda deixem a desejar (Greco, 2014). Podemos então concluir que, no Brasil não há ausência de suporte de conhecimento e formação ao empresariado, mesmo que esta percepção seja baixa (Greco, 2014). Contudo, o desenvolvimento tecnológico e os investimentos em Pesquisa e Desenvolvimento constitui um obstáculo a competitividade dos produtos nacionais no mercado global, com implicações sistêmicas que tendem a manter sua condição entre a periferia e a semiperifieria, mas ainda distante do centro do sistema mundial.

\section{A CPLP no sistema econômico mundial}

O sistema mundial moderno obedece a uma lógica de competição entre empresas e países (Wallerstein, 2005). Este sistema competitivo se baseia principalmente em dois mecanismos: (1) produtividade e (2) inovação. Enquanto o primeiro mecanismo pode ser entendido como capacidade de produzir mais (mercadorias) com menos (recursos ou em menor tempo), o mecanismo das inovações representa a capacidade inventiva de criar novos produtos, funções, designs ou tecnologias incorporadas em mercadorias que despertam o interesse de consumo dos mercados. Sob o ponto de vista da divisão 
internacional do trabalho, observamos que os países da CPLP, de um modo geral se destacam por oferecer ao mercado mundial mercadorias cujo potencial de competitividade reside basicamente na expansão da produtividade. Enquanto que outro grupo de países, industrializados, tem detido o monopólio da oferta de mercadorias inventivas e inovadoras. Na teoria do Sistema Mundo estes países industrializados são denominados centrais (core), enquanto que as nações menos industrializadas são denominadas de periféricas. Entre elas se encontram países que se esforçam para fazer esta transição da periferia para o centro, denominadas então de países semiperiféricos (Wallerstein 2005). As nações que conseguem assegurar um ambiente propício à inovação garantem para si melhores condições na disputa pelos mercados, cada vez mais integrados comercialmente.

As economias centrais se caracterizam por deterem em suas fronteiras as sedes das grandes companhias industriais, especialmente àquelas empresas que se destacam pela inovação de seus produtos. No entanto muitas destas empresas possuem parques industriais em países mais a periferia do sistema. Esta centralidade na capacidade de inovação e criatividade na produção industrial se estende as marcas da nova economia. Assim, empresas inovadoras e de alcance global, que oferecem serviços intangíveis, tais como a Google ou o Facebook ou ainda aquelas que produzem sistemas operacionais indispensáveis como a Microsoft; representam a nova face do capitalismo tecnológico, por vezes denominada de nova economia.

Os efeitos deste dinamismo empreendedor de primeira ordem nas economias destas nações centrais vão além dos lucros e riquezas que para estes países fluem. Uma parte desta riqueza é distribuída para as classes menos privilegiadas que ocupam a base da pirâmide social destas sociedades. Esta seria uma das explicações para o fato de muitos países desenvolvidos possuírem políticas sociais abrangentes. Estas, por sua vez, são sustentadas pelos excedentes econômicos capitalizados através dos negócios das suas companhias nacionais que exportam e remetem da periferia do sistema o lucro de suas subsidiárias. No fluxo global da riqueza há uma distribuição desigual da riqueza global. Um fenômeno observado desde as primeiras décadas do século XX e que já foi nomeada de deterioração dos termos de intercâmbio (Prebish, 1968). Precisamos salientar que a visão de Raúl Prebish (1901-1986) considerava apenas dois grupos de países (centrais e periféricos), enquanto que a teoria de Immanuel Wallerstein acrescenta uma categoria intermediária chamada de semiperifeira. Na visão do Cepalisa Prebish, os países centrais 
se caracterizavam pela sua capacidade industrial enquanto que as nações periféricas ainda possuíam sua balança comercial fortemente marcada pelo peso dos produtos primários (agropecuária ou extrativismo). A justificativa de Wallerstein para sua categoria média é a de que algumas nações possuem sua economia composta por um misto de produtos industrializados e outros primários (Wallerstein, 2005). Um exemplo de país semiperiférico na CPLP é Portugal. O caso brasileiro seria mais complexo. Pois nas últimas décadas o país tem passado por um processo de desindustrialização (Bonelli e Pessôa, 2010). Este fenômeno põe em evidência o dinamismo do sistema mundial moderno, no qual países podem ora aproximar-se dos países centrais, ora afastar-se desta posição, de acordo com a composição de seu sistema produtivo. Ao observarmos a composição das balanças comerciais e o grau de industrialização dos países da CPLP observamos a forte contribuição dos produtos primários (Portugal, 2015). Deste modo, com a exceção de Portugal e do discutível caso brasileiro, os demais países da CPLP ainda possuem economias do tipo periférica, baseada principalmente na exportação de produtos agrícolas ou fruto do extrativismo.

Enquanto isso, os países centrais avançam rumo a um novo estágio de desenvolvimento de suas estruturas produtivas. Referimo-nos a nova economia. Expressão empregada para designar as empresas de Tecnologia, informação e comunicação (TICs) e a toda a gama de serviços viabilizados por estas novas companhias. As expectativas criadas por este novo setor tecnológico fizeram com que a Bolsa de valores de Nova York criasse um índice separado para medir o desempenho das ações deste setor (NASDAQ). Alguns autores chegam mesmo a afirmar que a realidade atual do desenvolvimento econômico e tecnológico das sociedades centrais; tornaram obsoletos muitos conceitos das teorias econômicas clássicas (Laitman, 2013). Michael laitman e seus colaboradores afirmam que a nova economia descortina uma série de possibilidades para o desenvolvimento global. Dentre eles destacamos: um padrão de vida justo para todos, custo de vida reduzido, diminuição das desigualdades sociais, gerenciamento transparente dos orçamentos públicos, incremento da riqueza, aprimoramento das relações entre empresa e governo e entre patrões e empregados, estabilidade econômica de longo prazo, consumo equilibrado e responsável e finalmente, maior felicidade para todos (Laitman, 2013). Algumas destas inovações podem ser observadas em pequena escala nas companhias do Vale do Silício (Silicon Valley), na Califórnia. Embora ainda distante de se tornar uma regra geral, sinalizam uma gama de possibilidades, ao menos para as economias centrais. 
No entanto precisamos lembrar que todo este desenvolvimento só surgiu nas nações centrais devido a um ambiente de negócios que permitiu a emergência de novos modelos de regulação das forças produtivas.

Quando comparamos a situação de países como o Brasil, que ainda enfrenta obstáculos governamentais tais como a burocracia e culturais, tais como o baixo investimento em Pesquisa e Desenvolvimento, notamos que ainda estamos distantes da criação das condições mínimas para o salto da nova economia. No entanto, a existência de um Fórum como o da CPLP, pode permitir a emergência de políticas comuns de desenvolvimento, de intercâmbio justo capaz de aumentar a participação do grupo na economia mundial.

\section{Conclusão}

Refletindo criticamente acerca dos dados levantados, podemos concluir que o Brasil apresenta um grande potencial para o desenvolvimento de atividades empreendedoras em diversos campos ou setores econômicos. Uma vez que o país se encontra entre as nações em desenvolvimento, dotada de vastos recursos humanos e naturais, cujos potenciais ainda se encontram aproveitados de modo pouco satisfatório. A transição de uma sociedade marcada pelo empreendedorismo de oportunidade para uma capaz de gerar inovação ainda é um desafio. Se considerarmos o crescente grau de interação econômica do nosso tempo e a vasta rede de relações multilaterais firmada pelo país nas últimas décadas (CPLP, MERCOSUL, UNASUL), a capacidade de inovação apresenta um potencial de internacionalização dos negócios locais, em uma escala ainda pouco conhecida ou apenas restrita a alguns setores e ao espectro das grandes empresas. Um maior investimento na preparação dos quadros empresariais também poderá influir em uma maior sobrevida das empresas brasileiras, profissionalizando até mesmo aqueles que empreendem por necessidade mais do que por oportunidade e vocação. Notamos também que uma grande parte dos obstáculos ao desenvolvimento do empreendedorismo se deve a carências por parte do próprio Estado brasileiro. Tal qual é o caso da burocracia, do excesso de impostos, da necessidade de estruturas complexas para cumprir obrigações acessórias e informes tributários, além dos elevados juros pagos pelos investidores que querem iniciar um negócio. Estas condições externas a responsabilidade do empresário, se constituem como elementos decisivos para o seu sucesso. Mais uma vez, percebemos a atualidade das reflexões de Joseph Schumpeter, que em sua Teoria do Desenvolvimento 
Econômico, publicada em sua primeira edição no ano de 1934, obra na qual destaca o ambiente institucional, como um fator relevante para o desenvolvimento dos negócios e das nações. Não basta a eficiência do empresariado e sua disposição em correr riscos, se a ordem institucional the trava as possibilidades e iniciativas. No caso brasileiro existem organizações da Sociedade Civil tais como o SEBRAE e o Sistema "S", formado por SENAC; SESI; SESC e SENAI; completados também pelas universidades públicas e privadas, que apóiam o empreendedorismo. No entanto todo este suporte ainda não se fez suficiente para vencer as barreiras impostas pela ineficiência das regras governamentais e sua burocracia que travam iniciativas em diferentes setores. Cabe a classe do empresariado organizado, através de seus mecanismos representativos; chamar a atenção dos governos para esta pauta. Uma vez que, neste caso, o Estado tem se tornado um obstáculo ao desenvolvimento econômico da atividade empreendedora e do próprio país.

\section{Referências bibliográficas}

Ahmad, N.; Seymour, R. G. (2008). Defining Entrepreneurial Activity. Paris: OCDE.

Bessant, John; Tidd, Joe (2009). Inovação e Empreendedorismo. São Paulo: Artmed.

Bonelli, Régis e Pessôa, Samuel de Abreu (2010). Desindustrialização no Brasil. Rio de Janeiro: IBRE/FGV.

Dornelas, José Carlos A. (2001). Empreendedorismo: transformando idéias em negócios. Rio de Janeiro: Elsevier.

Filon, Louis Jacques (1999). Empreendedorismo: empreendedores e proprietáriosgerentes de pequenos negócios. Revista de Administração. Vol. 34 (2), (Abril-Junho), pp. 05-28.

Greco, Simara Maria de Souza S. (Coord.) et al. (2014). Empreendedorismo no Brasil. Curitiba: IBQP.

IBGE (2014). Estatísticas do Empreendedorismo 2012. Rio de Janeiro: IBGE.

Laitman, Michael et al. (2013). Os Beneficios da Nova Economia. Nova York: ARI.

Marx, Karl. O Capital: critica da economia política. Rio de Janeiro: Civilização brasileira, 2014.

Portugal (2015). Estatísticas do Comércio Internacional. Lisboa GPP. 
Prebish, Raúl (1968). Dinâmica de desenvolvimento Latino-Americano. Fundo de Cultura.

Schumpeter, Joseph A (2010). The Theory of Economic Development. New York: PanAmerican.

Wallerstein, Immanuel (2005). Análisis de Sistema-mundo: una introdución. México: siglo veinte uno. 